\title{
Implant of Polymer Containing Pentacyclic Triterpenes from Eugenia punicifolia Inhibits Inflammation and Activates Skeletal Muscle Remodeling
}

\author{
Paulo Emílio C. Leite • Katia G. Lima-Araújo • \\ Guilherme R. França · Jussara Lagrota-Candido • \\ Wilson C. Santos · Thereza Quirico-Santos
}

Received: 11 June 2013/Accepted: 24 September 2013/Published online: 16 May 2014

(C) L. Hirszfeld Institute of Immunology and Experimental Therapy, Wroclaw, Poland 2014

\begin{abstract}
Sustained chronic inflammation induces activation of genes involved in cellular proliferation and apoptosis, thereby causing skeletal muscle degeneration. To investigate in vitro effects of isolated pentacyclic triterpenes from Eugenia punicifolia $(E p-C M)$ upon signaling pathways involved in the regulation of skeletal muscle cell line proliferation, and in vivo muscular tissue remodeling. C2C12 cells were seeded on eight-well plates and $\left[{ }^{3} \mathrm{H}\right]-$ thymidine incorporation, TUNEL assays, mitochondria viability, zymography for matrix metalloproteases (MMPs), Western blot analysis for MAPKinase signaling pathway, NFkB activation and HMGB1 production subsequently determined under basal conditions and after $E p$ $C M$ treatment. A polymer containing Ep-CM was implanted on the volar surface of gastrocnemius muscles
\end{abstract}

P. E. C. Leite · G. R. França · T. Quirico-Santos ( $₫)$

Department of Cellular and Molecular Biology,

Institute of Biology, Fluminense Federal University,

Niterói, RJ 24020-141, Brazil

e-mail: tquirico@vm.uff.br

K. G. Lima-Araújo · W. C. Santos

School of Pharmacy, Fluminense Federal University,

Niterói, RJ, Brazil

J. Lagrota-Candido

Department of Immunobiology, Institute of Biology,

Fluminense Federal University, Niterói, RJ, Brazil

W. C. Santos

Instituto Teófilo Hernando, Universidad Autónoma de Madrid,

Madrid, Spain

Present Address:

P. E. C. Leite

Instituto Nacional de Metrologia, Qualidade e Tecnologia

(INMETRO-RJ), Rio de Janeiro, Brazil subjected to acute injury induced by bupivacaine for local slow and gradual release of bioactive compounds, and mice killed 4 days after surgery. Ep-CM inhibited proliferation of $\mathrm{C} 2 \mathrm{C} 12$ myoblast cell line in a dose-dependent manner, confirmed by reduction of $\left[{ }^{3} \mathrm{H}\right]$-thymidine uptake without affecting cell viability or inducing apoptosis. The cytostatic effect of Ep-CM occurred mainly via inhibition of phosphorylated extracellular signal-regulated kinase (pERK) activation and DNA synthesis, possibly inhibiting the G1 phase of the cell cycle, since $E p-C M$ increased pAkt and p2 $7^{\text {kip } 1}$ but reduced Cyclin D1. Ep-CM in vitro treatment increased MMP-9 and MMP-2 activities of C2C12 myoblast cells, but reduced in vivo MMP-9 activity and acute muscular inflammation. Besides cytostatic and antiinflammatory effects, $E p-C M$ pentacyclic triterpenes also contributed to degradation of basement membrane components by activating mechanisms of skeletal muscle remodeling in response to local injury.

Keywords Pentacyclic terpenes - C2C12 myoblasts . Inflammation - Skeletal muscle - Muscular injury · Muscle remodeling $\cdot$ Bioengineering

\section{Introduction}

Natural compounds from plant extracts often display distinct pharmacological activities with possible therapeutic applications in various pathologies (Rahimi et al. 2010). The Eugenia genus of Myrtaceae family, a shrub growing predominantly in tropical and sub-tropical forests from Brazil, is largely used in folk medicine as diuretic and hypoglycaemic remedy by some communities in the Amazon region (Bopp et al. 2009; Brito et al. 2007). Bioactive substances (flavonoids, steroids, terpenoids, tannins, 
anthraquinones) isolated from Eugenia leaves, bark or fruits are complex mixtures that exhibit diuretic, antimicrobial, trypanomicide, and antioxidant effects (Consolini and Sarubbio 2002; dos Santos et al. 2012). Such complexity often makes difficult to explain the diversity of properties. For instances, aqueous extract from E. punicifolia leaves hydrodistillation enhanced cholinergic nicotinic neurotransmission in rat diaphragm (Grangeiro et al. 2006), but increased $\mathrm{K}^{+}$-elicited secretion without enhancing the whole-cell inward calcium current in adrenal chromaffin cells (de Pascual et al. 2012), and further exerted a potent antiinflammatory activity in skeletal muscles of dystrophic mutant mdx mice through a yet unknown mechanism.

In response to injury, changes in the microenvironment promote activation of resident cells which release growth factors, cytokines and matrix metaloproteases that influence leukocyte migration and tissue remodeling (Azouz et al. 2004). This study aimed to determine Ep-CM effect upon activation of mechanisms influencing skeletal muscle repair. We used a $\mathrm{C} 2 \mathrm{C} 12$ myoblast cell line to investigate in vitro effects of Ep-CM compound on cell behavior and activation of signaling pathways, and the regenerative capacity of skeletal muscles using a self-limited injury induced by bupivacaine.

\section{Materials and Methods}

Drugs and Reagents

Dimethyl sulfoxide (DMSO) was purchased from Sigma Chem. Co. (Saint Louis, MO, USA); $\left[{ }^{3} \mathrm{H}\right]$-thymidine $(0.5 \mu \mathrm{Ci})$ from Amersham Biosciences (Baie D'Urfe, QC, Canada); Dapi (4',6-diamidino-2-phenylindole) from Pierce Biotechnology (Rockford, IL, USA); Dulbecco's modified Eagle's medium (DMEM) and supplement fetal bovine serum from Gibco BRL (Grand Island, NY, USA), and MEK1-specific inhibitor PD98059 was purchased from New England Biolabs (Beverly, MA, USA). All other reagents were of analytical grade.

\section{Plant Material and Extract Preparation}

The leaves of the E. punicifolia were supplied by the Centro de Instrução de Guerra na Selva (CIGS, Manaus, AM, Brazil) and identified at the National Museum (Rio de Janeiro Federal University, Brazil). Official authorization for scientific investigation with plant components was given by the government environmental institution (IBAMA, Brazil), registration 16602-1 with a voucher specimen deposited at the National Museum (Rio de Janeiro, Brazil). Crude essential oil from fresh leaves was processed for extraction of the organic phase at room temperature with solvents of increasing polarity beginning with hexane, dichloromethane and methanol. Extracts were evaporated to dryness and the residues stored at $4{ }^{\circ} \mathrm{C}$. Stock solutions $(1 \mathrm{mg} / \mathrm{mL})$ were prepared in $10^{-2} \mathrm{M}$ DMSO. HPLC-grade methanol (E. Merck, Darmstadt, Germany) was used for the HPLC analysis. Deionized water was purified by Milli-Q system (Millipore, Bedford, MA, USA). Structural characterization of dichloromethanic isolates was established based on infrared spectroscopy, mass spectrometry and ${ }^{1} \mathrm{H}$ $(500 \mathrm{MHz})$ and ${ }^{13} \mathrm{C}(125 \mathrm{MHz})$ nuclear magnetic resonance, that identified a pentacyclic triterpene hydrocarbon (barbinervic acid) as major component.

\section{Cell Culture}

Mouse myoblastoma cells (C2C12) were maintained as subconfluent monolayer in DMEM containing $4.5 \mathrm{~g} / \mathrm{L}$ glucose, L-glutamine (Sigma, St. Louis, MI, USA) supplemented with $10 \%$ fetal bovine serum, antibiotics $50 \mathrm{U} /$ $\mathrm{mL}$ penicillin and $50 \mathrm{mg} / \mathrm{mL}$ streptomycin, and maintained at $37{ }^{\circ} \mathrm{C}$ in a $5 \% \mathrm{CO}_{2}$ humidified atmosphere. Cell cultures were performed on 8-wells slide chamber (Nunc Inc., Naperville, IL, USA) for cell morphology, immunofluorescence and Terminal deoxynucleotidyl transferase mediated dUTP nick-end labeling (TUNEL); 24-well culture plates for zymography, $\left[{ }^{3} \mathrm{H}\right]$-thymidine incorporation, cell membrane and mitochondria viability; and in 6-well culture plates (Becton-Dickinson, Franklin Lakes, NJ, USA) for Western blot assays.

\section{Cell Morphology and Viability}

$\mathrm{C} 2 \mathrm{C} 12$ cells $\left(5 \times 10^{4}\right)$ were treated with vehicle (DMSO) or $100 \mu \mathrm{g} / \mathrm{mL} \mathrm{Ep-CM}$ during $24 \mathrm{~h}$ at $37{ }^{\circ} \mathrm{C}$ in a $5 \% \mathrm{CO}_{2}$ incubator. Cells were fixed with $4 \%$ paraformaldehyde and $2 \%$ glutaraldehyde in $0.1 \mathrm{M}$ phosphate buffered saline (PBS) for $30 \mathrm{~min}$, followed by PBS wash and nuclei staining with Dapi. Phase contrast images were obtained using a Nikon Eclipse TE2000-U microscope. Cellular viability was determined by live-dead kit according to manufacturer recommendations (Molecular Probes, Eugene, OR, USA). Live cells were distinguished by intense uniform green fluorescence and cells with damaged membranes by red fluorescence nuclei. Fluorescent images were obtained using a Nikon Eclipse TE2000-U microscope and merged on Adobe Photoshop CS5.

$\left[{ }^{3} \mathrm{H}\right]$-Thymidine Incorporation and Mitochondrial Activity

C2C12 cells $\left(10^{5}\right)$ were treated with different concentrations of $E p-C M$ or vehicle during $24 \mathrm{~h}$, and next incubated with $\left[{ }^{3} \mathrm{H}\right]$-thymidine $(0.5 \mu \mathrm{Ci})$ for $60 \mathrm{~min}$ at $37{ }^{\circ} \mathrm{C}$ in $5 \%$ 
$\mathrm{CO}_{2}$ incubator. Cultures were washed three times with $1 \mathrm{~mL}$ DMEM buffered with $25 \mathrm{mM}$ Hepes $\mathrm{pH} 7.4$, dissolved with $0.1 \mathrm{~mL}$ of $0.4 \mathrm{~N} \mathrm{NaOH}$ and further treated with $50 \%$ TCA solution and incubated for $30 \mathrm{~min}$ at $4{ }^{\circ} \mathrm{C}$. The radioactivity was determined by scintillation spectroscopy (Packard, model 1600 TR).

Mitochondrial activity was measured using MTT [3(4,5-dimethylthiazol-2-yl)-2,5-diphenyltetrazolium bromide, Sigma, St Louis, MI, USA] tetrazolium salt reduction method (Mosmann 1983). C2C12 cells $\left(5 \times 10^{4}\right)$ were treated with crescent concentrations of $E p-C M$ during $24 \mathrm{~h}$ at $37{ }^{\circ} \mathrm{C}$ in a $5 \% \mathrm{CO}_{2}$ incubator, then washed with PBS pH 7.6 and incubated with $1.5 \mathrm{mg} / \mathrm{mL}$ MTT. After $4 \mathrm{~h}$, cells were treated with alcoholic-acid lyse solution (12 $\mathrm{N} \mathrm{HCl}$ and isopropyl alcohol 6:1) and soluble formazan product estimated by the absorbance at $570 \mathrm{~nm}$ after subtracting the absorbance at $650 \mathrm{~nm}$.

\section{Western Blot Analysis}

C2C12 cells $\left(5 \times 10^{5}\right)$ cells were plated and after specific treatment homogenized for immunoblot analysis. Primary polyclonal rabbit antibodies for cleaved caspase-3 (Asp175 at 1:1,000) and extracellular signal-regulated kinase 1 and 2 (ERK1/2 at 1:2,000) were from Cell Signaling Technology (Beverly, MA, USA); for Cyclin D1 (sc-717 at 1:1,000), NFkB p65 (F-6 at 1:500) from Santa Cruz Biotechnology (Santa Cruz, CA, USA), and monoclonal antibodies: rabbit anti-Akt (pan C67E7 at 1:2,000), antipAkt (Ser473 D9E at 1:2,000) and mouse anti-phosphorylated (p)ERK1/2 (Thr202/Tyr204 E10 at 1:2,000) from Cell Signaling Technology (Danvers, MA, USA); antip2 $7^{\text {kip1 }}(57 /$ Kip1/p27 at 1:4,000) from BD Biosciences (Franklin Lakes, NJ, USA), and anti-HMGB1 (MAb1690 at 1:500) from R\&D Systems (Minneapolis, MN, USA).

Peroxidase-conjugated donkey anti-rabbit at 1:3,000 and goat anti-mouse at 1:3,000 (Zymed, San Francisco, CA, USA) were also used. Bands were identified by chemiluminescence followed by subsequent film exposure for $5 \mathrm{~min}$. As negative control, samples were incubated without primary antibodies. Equal loading of protein was assessed on stripped blots by immunodetection of $\beta$-actin using goat anti-human polyclonal peroxidase-conjugated antibody at 1:1,000 from Santa Cruz Biotechnology.

\section{TUNEL for In Situ Detection of Apoptosis}

Programmed cell death was measured using a TUNEL apoptosis detection kit (DNA fragmentation/fluorescence staining) to identify apoptotic cells. $\mathrm{C} 2 \mathrm{C} 12$ cells $\left(5 \times 10^{4}\right)$ were plated and treatments conducted for further TUNEL analysis according to recommendations (Upstate, Temecula, USA). Cells were counterstained with Dapi and images were randomly obtained with a Nikon Eclipse TE2000-U microscope with identical time exposure and image settings and merged on Adobe Photoshop CS5.

Immunofluorescence

$\mathrm{C} 2 \mathrm{C} 12$ cells $\left(5 \times 10^{5}\right)$ were fixed for $30 \mathrm{~min}$, washed with PBS and incubated for $1 \mathrm{~h}$ with blocking buffer PBST $(0.05 \%$ Triton X-100 in PBS, containing $5 \%$ normal goat serum). Cells were incubated overnight at $4{ }^{\circ} \mathrm{C}$ with polyclonal rabbit anti-NFkB p65 (at 1:400) from Santa Cruz Biotechnology; or monoclonal mouse antibodies antipERK1/2 (Thr202/Tyr204 E10; Cell Signaling Technology), and anti-HMGB1 (MAb1690 at 1:500; R\&D Systems) in blocking buffer at $4{ }^{\circ} \mathrm{C}$ overnight. Thereafter samples were incubated with secondary antibodies donkey anti-rabbit IgG Alexa 568, 488 or goat anti-mouse $\operatorname{IgG}$ Alexa 488-labeled, all at 1:200 (Molecular Probes, Eugene, OR, USA) and cells were counterstained with Dapi.

\section{Animal Care}

C57BL/10 mice were maintained in the Cellular Pathology animal house facilities at Universidade Federal Fluminense, with a light/dark cycle of $12 \mathrm{~h}$ at constant temperature $\left(21^{\circ} \mathrm{C}\right)$. Each cage housed up to four mice from same age and offspring to minimize stress. All experimental procedures and handling of animals were approved by the Institutional Animal Care Committee (protocol 175/09) and conducted according to the Brazilian Committee of Animal Experimentation Ethics Board in agreement with international regulations.

\section{Preparation of Elvax Containing Ep-CM}

Ethylene-vinyl acetate copolymer (Elvax 40W, DuPont, Pinheiros, SP, Brazil) was washed in $95 \%$ alcohol with multiple changes during 7 days. Elvax was dissolved in dichloromethane to give a $10 \%$ solution. Fifty $\mu \mathrm{E} \mathrm{Ep-CM}$ $(2 \mathrm{mg} / \mathrm{mL}$ ) was dissolved in $50 \mu \mathrm{l}$ DMSO with $1 \%$ Fast Green added to the solution to help visualizing Elvax slices. Preparation was mixed up for $1 \mathrm{~min}$, then immediately placed in dry ice for $30 \mathrm{~min}$, stored at $-20{ }^{\circ} \mathrm{C}$ for 5 days, further submitted to low-vacuum pressure for $16 \mathrm{~h}$ at $0{ }^{\circ} \mathrm{C}$ followed by preparation of $200 \mu \mathrm{m}$ cryostat sections. Elvax slices were stored at $-20{ }^{\circ} \mathrm{C}$ until implantation in the gastrocnemius muscle of $\mathrm{C} 57 \mathrm{BL} / 10$ mice.

Induction of Muscular Lesion and $E p$-CM In Vivo Treatment

Male C57BL/10 mice at 6 weeks old were anesthetized by intraperitoneal injection with ketamine $(100 \mathrm{mg} / \mathrm{kg})$ and 
xylazine $(5 \mathrm{mg} / \mathrm{kg})$. Muscular lesion was performed as previously described (Mussini et al. 1987) with $80 \mu \mathrm{L}$ $0.5 \%$ bupivacaine hydrochloride (Bupivacaine, Sigma, USA) in the central region of both gastrocnemius muscles.

Immediately after the induction of muscular lesion with bupivacaine (Bp), a small incision in the skin was made with sterile steel blade, Elvax polymer manufactured with $2 \mathrm{mg} / \mathrm{mL} E p$-CM was carefully placed on the gastrocnemius muscle for local slow release of substances from $E p$ $C M$ (Leite et al. 2010), and the incision closed with cyanoacrylate ester. Mice were killed 4 days after surgery, and both gastrocnemius muscles collected.

Histological Staining and Analysis

Gastrocnemius muscles were carefully removed and fixed in formalin-buffered Millonig fixative ( $\mathrm{pH}$ 7.2) for $24 \mathrm{~h}$. Five $\mu \mathrm{m}$-thick sections of wax-embedded material were stained with hematoxylin-eosin and sirius red for collagen. High-definition whole area images of all cross-sections from each mouse at a time point were obtained from individual photomicrographs with a microdigital camera mounted on a Zeiss Axioplan microscope (Zeiss, Oberkochen, Germany) using a $\times 20$ objective.

\section{Gelatin Zymography}

Gastrocnemius muscles were removed, weighed, immediately frozen in liquid nitrogen and homogenized (1:10 w:v) in a non-reducing extraction buffer $\mathrm{pH} 6.8(100 \mathrm{mM}$ Tris$\mathrm{HCl} \mathrm{pH}$ 7.6, $200 \mathrm{mM} \mathrm{NaCl}, 100 \mathrm{mM} \mathrm{CaCl} 2,1 \%$ Triton $\mathrm{X}-100)$. After centrifugation protein content in the supernatant was determined and concentration adjusted in a nonreducing dilution buffer (100 mM Tris, $10 \%$ glycerol, $4 \%$ sodium dodecyl sulfate, $0.1 \%$ bromophenol blue). Conditioned medium from cell cultures were obtained $24 \mathrm{~h}$ after treatment and diluted $(1: 10 \mathrm{v}: \mathrm{v})$ in non-reducing dilution buffer.

The same concentration of muscle extracts $(60 \mu \mathrm{g})$ and conditioned medium from control (DMSO vehicle) and $E p$ $C M$ treated cell cultures were loaded per lane. SDS-PAGE zymography was performed as described previously (Leite et al. 2010). Gelatinase activity was visualized as unstained bands on a blue background, representing areas of substrate protein proteolysis.

\section{Quantitative and Statistical Analysis}

All experiments were conducted in quadruplicates. Quantitative analysis for $\left[{ }^{3} \mathrm{H}\right]$-thymidine incorporation, mitochondria viability, Western blot and zymography was performed using the image-analysis software Scion Image for Windows (Scion Corporation, National Institutes of
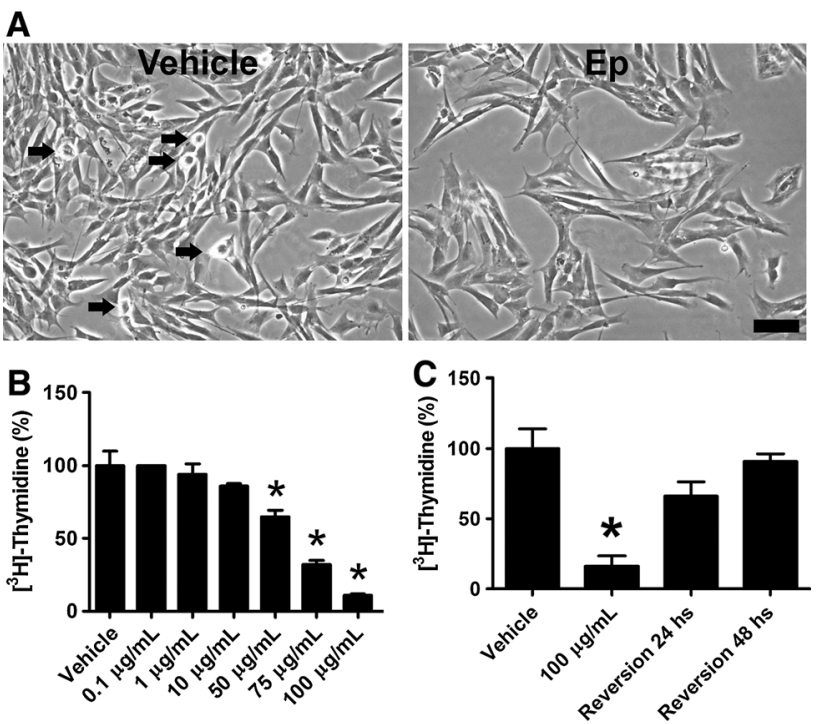

Fig. $1 E p-C M$ inhibits $\mathrm{C} 2 \mathrm{C} 12$ cell proliferation. a Phase contrast images from $\mathrm{C} 2 \mathrm{C} 12$ cells $24 \mathrm{~h}$ after treatment with DMSO vehicle or Ep-CM $100 \mu \mathrm{g} / \mathrm{mL}$. Black arrows indicate proliferating cells. Scale bar $100 \mu \mathrm{m}$. b [ $\left.{ }^{3} \mathrm{H}\right]$-thymidine incorporation following treatment with different $E p$ - $C M$ concentrations. c $\left[{ }^{3} \mathrm{H}\right]$-thymidine incorporation after 24 and $48 \mathrm{~h}$ washout assay. One-way ANOVA test showed $p<0.0005$ for $\left[{ }^{3} \mathrm{H}\right]$-thymidine incorporation assays. Unpaired Student's $t$ test analyses $(* p<0.0005)$. Results are represented as mean $\pm \mathrm{SD}$ ( $n=3$ in quadruplicates for all assays)

Health; Bethesda, MD, USA). GraphPad Prism 5 (GraphPad software Inc.) was used to calculate mean and standard deviations. One-way ANOVA and unpaired Student's $t$ test were applied to obtain statistical significance of means. Differences were considered to be statistically significant at the 0.05 level of confidence.

\section{Results}

Ep-CM Reduces Myoblast Cell Proliferation

Addition of $100 \mu \mathrm{g} / \mathrm{mL} E p-C M$ in the culture medium reduced $\mathrm{C} 2 \mathrm{C} 12$ cell density (Fig. 1a) and cell proliferation in a concentration-dependent manner reaching $89 \pm 0.6 \%$ $(p<0.0005)$ inhibition at $100 \mu \mathrm{g} / \mathrm{mL}$ (Fig. 1b). Inhibition of cell proliferation assessed by $\left[{ }^{3} \mathrm{H}\right]$-thymidine incorporation only occurred while $E p-C M$ was present, and washing out partially reversed the effect after $24 \mathrm{~h}$ $(66 \pm 10 \%, \quad p<0.0005)$ and totally after $48 \mathrm{~h}$ (91 $\pm 5 \%, p<0.0005$, Fig. 1c).

\section{Effect of Ep-CM on Cell Viability and Apoptosis}

$\mathrm{C} 2 \mathrm{C} 12$ cells were either treated with 75 and $100 \mu \mathrm{g} / \mathrm{mL}$ of $E p-C M$ or DMSO vehicle. Supernatants were collected, centrifuged and resuspended for cell counting. We 


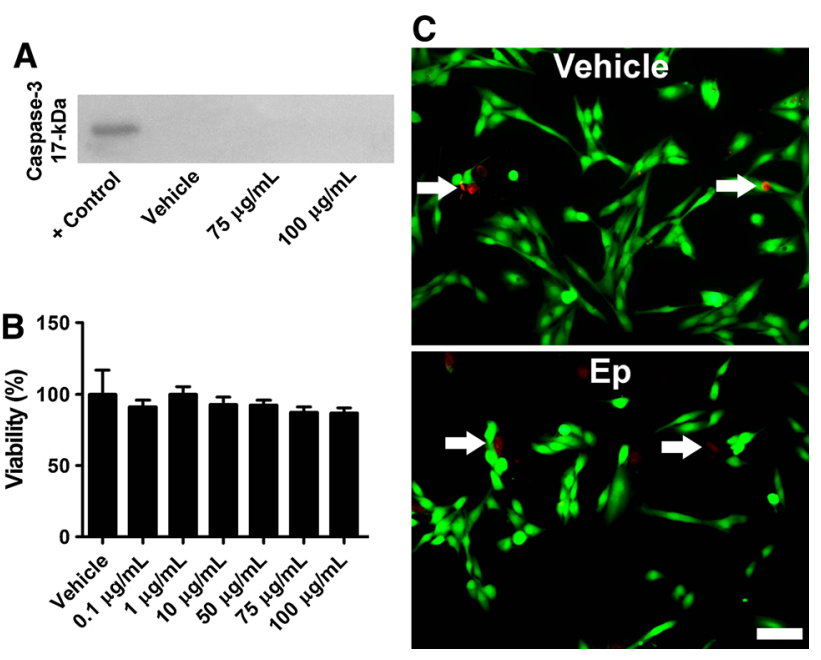

Fig. 2 Effect of Ep-CM in $\mathrm{C} 2 \mathrm{C} 12$ viability and apoptosis. a Immunoblot analysis for cleaved caspase-3 after Ep-CM treatment. Cells treated with etoposide were used as positive control for apoptosis. $43-\mathrm{kDa} \beta$-actin was used as loading control. b Mitochondrial activity after $E p-C M$ treatment with different concentrations. Results are represented as mean $\pm \mathrm{SD}$ ( $n=3$ in quadruplicates for all assays). c Cellular viability after treatment with vehicle DMSO or $E p-C M$ $100 \mu \mathrm{g} / \mathrm{mL}$. Green cells and red nuclei indicate viable and non-viable cells, respectively. White arrows show red nuclei and non-viable cells. Scale bar $100 \mu \mathrm{m}$

observed few cells in the supernatant and the degree of apoptosis assessed by TUNEL was similar in detached cells from both groups. The amount of fragmented nuclei was very low in both groups (data not shown) with undetectable levels of cleaved caspase-3 assessed by Western blot (Fig. 2a). Mitochondrial activity was assessed by MTT assay (Fig. 2b), cellular viability by fluorescent enzymatic reaction of intracellular calcein (viable cells, green) and DNA intercalation with ethidium bromide EthD-1 for nonviable cells (red nuclei, Fig. 2c). Ep-CM treated cells did not show significant difference in mitochondrial and cellular viability in comparison with control cells treated with vehicle.

\section{Effect of $E p-C M$ on Metalloproteases Production}

Matrix metalloproteases (MMPs) are critical for tissue remodeling in both physiological and pathological processes. Metalloproteases are secreted in a latent form and require cleavage of an $\mathrm{NH}_{2}$ terminus peptide for activation. The exposure of proenzymes to SDS during gel separation leads to activation without proteolytic cleavage (Talhouk et al. 1992) with appearance of bands corresponding to 100-kDa (MMP-9), 66-kDa (pre-pro-MMP-2), 60-kDa (pro-MMP-2) and 55-kDa (active-MMP-2) (Kherif et al. 1999).

Treatment of $\mathrm{C} 2 \mathrm{C} 12$ cells with $100 \mu \mathrm{g} / \mathrm{mL}$ Ep-CM increased MMP-9 $(128 \pm 14 \%, p<0.005)$ and MMP-2
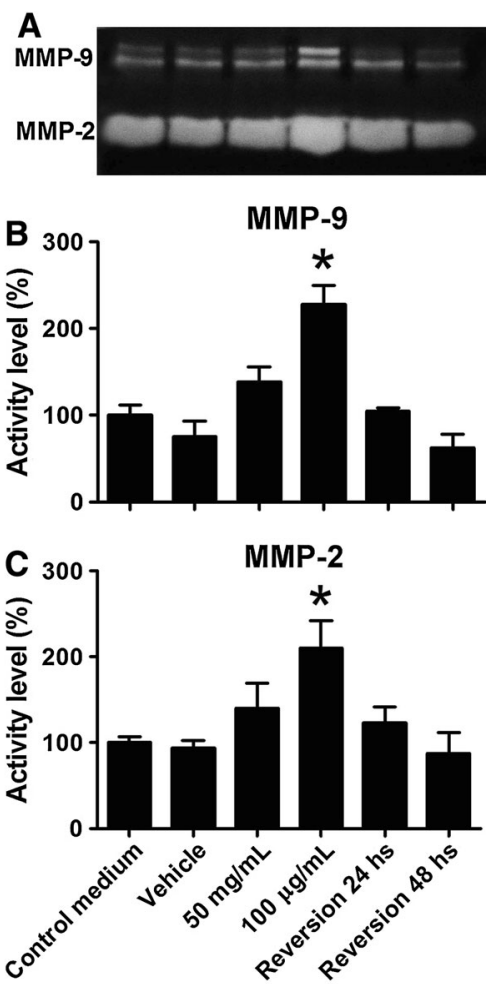

Fig. $3 E p-C M$ increases $\mathrm{C} 2 \mathrm{C} 12$ metalloproteases production in vitro. a Gelatin zymogram of conditioned medium with SBF $10 \%$ : control medium, cells without treatment; vehicle, treated with DMSO; 50 and $100 \mu \mathrm{g} / \mathrm{mL}$, treated with different concentrations of $E p-C M$; reversion 24- and 48-h, conditioned medium with Ep-CM discarded after $24 \mathrm{~h}$ and every $24 \mathrm{~h}$ added fresh medium for analysis. b MMP-9 and c MMP-2 activities. One-way ANOVA test showed $p<0.0005$ for both MMP-9 and MMP-2 analysis. Unpaired Student's $t$ test analyses $(* p<0.005)$. Results are represented as mean $\pm \mathrm{SD}(n=3$ in quadruplicates for all assays)

$(110 \pm 18 \%, p<0.005)$ activities in comparison with control groups (Fig. 3).

\section{Ep-CM Inhibits the MAPKinase Signaling Pathway}

PD98059, a classic specific inhibitor of MEK1 phosphorylation (Tortorella et al. 2001) reduced $\mathrm{C} 2 \mathrm{C} 12$ cell proliferation $(86 \pm 1 \%, p<0.0005)$ at $50 \mu \mathrm{M}$ without affecting cell viability (Fig. 4a). This result was similar to the effect induced by $E p-C M$ treatment on cellular proliferation. In the presence of $E p-C M$ was observed reduced phosphorylated extracellular signal-regulated kinase (pERK) expression in a dose-dependent manner reaching $72 \%( \pm 12 \%, p<0.005)$ at $100 \mu \mathrm{g} / \mathrm{mL}$ (Fig. 4b), a result further supported by reduced fluorescent signal which confirms the decrease of pERK protein levels detected by Western blot analysis (Fig. 4c). Both Ep-CM and PD98059 exert similar effect on MAPKinase signaling pathway regarding the phosphorylation of ERK protein. 

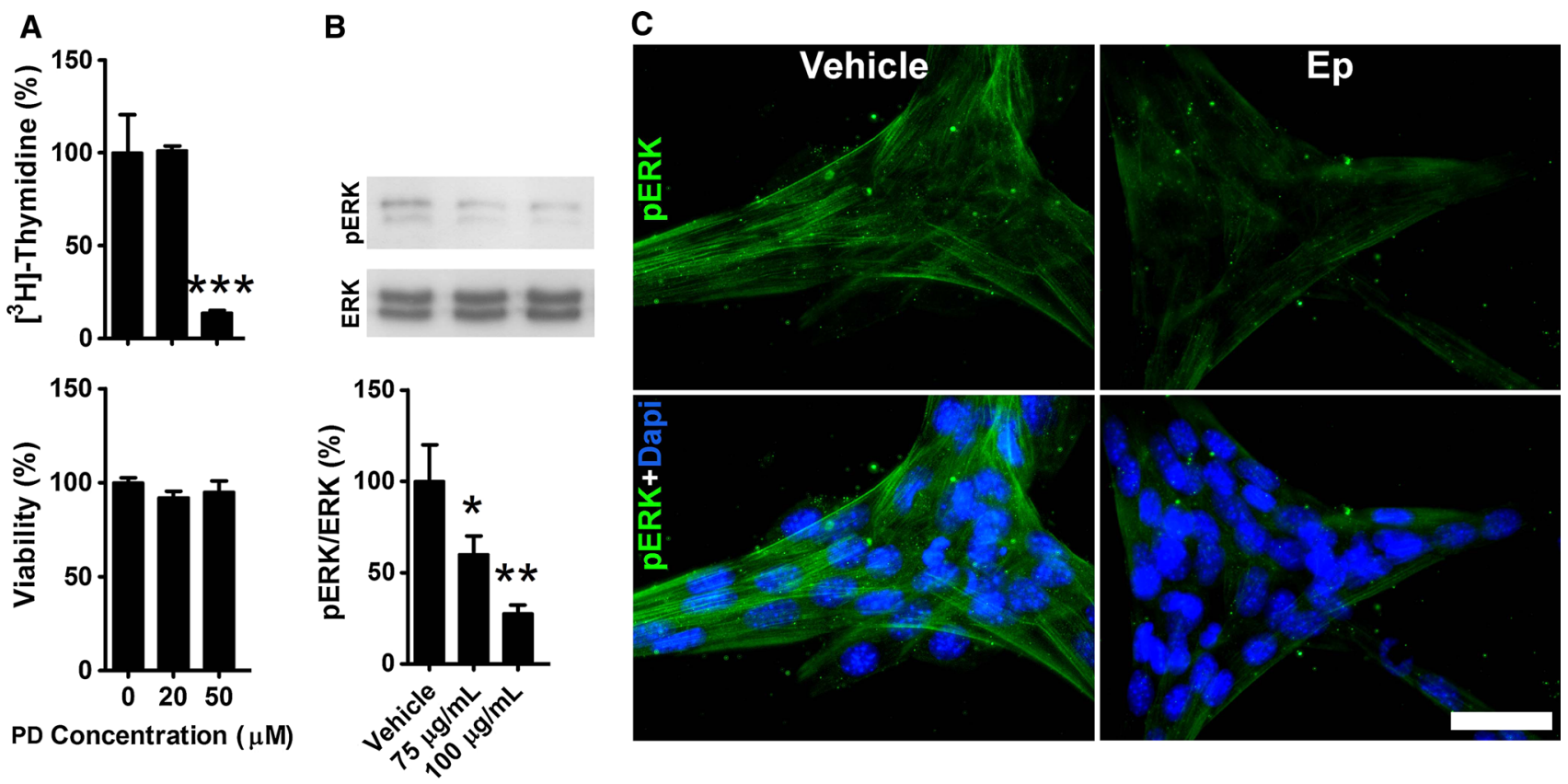

Fig. 4 Ep-CM extract inhibits MAPK signaling pathway. a On top $\left[{ }^{3} \mathrm{H}\right]$-thymidine incorporation and below mitochondria viability after treatment with 20 and $50 \mu \mathrm{L}$ of PD98059. b Immunoblot analysis of pERK content after $E p-C M$ treatment with 75 and $100 \mu \mathrm{g} / \mathrm{mL}$. Total ERK was used as loading control. c pERK immunocytochemistry and merged images with Dapi after treatment with vehicle or $100 \mu \mathrm{g} / \mathrm{mL}$ $E p-C M$. Negative control did not show immunoreactivity (data not

Effect of $E p$-CM in NFkB Activation and HMGB1 Production

$\mathrm{NF \kappa B}$ is a transcription factor related to cellular events controlling proliferation and inflammation (Lee et al. 2007), and HMGB1 is a molecule released from activated macrophage and necrotic cells with intrinsic proinflammatory activity, which can also be induced by NFKB nuclear translocation and activation (Wang et al. 2004). No alterations regarding nuclear/cytoplasmic localization of NFKB and HMGB1 were observed by immunofluorescence (Fig. 5a, b), and neither in the protein expression as assessed by Western blot on cells treated with Ep-CM (Fig. 5c).

\section{Ep-CM Influences Proteins that Regulate the Cell Cycle}

We observed a dose-dependent increase of $77 \%( \pm 20 \%$, $p<0.05)$ for pAkt, and $82 \%( \pm 10 \%, p<0.05)$ for $\mathrm{p} 27$ levels at $100 \mu \mathrm{g} / \mathrm{mL}$ (Fig. 6a, b). Conversely, Ep-CM treatment reduced cyclin D1 levels reaching $38 \%( \pm 9 \%$, $p<0.05)$ at $100 \mu \mathrm{g} / \mathrm{mL}$ in comparison with control vehicle (Fig. 6c). These results indicate that the cytostatic effect of $E p-C M$ is partly due to the inhibition of $\mathrm{C} 2 \mathrm{C} 12$ at $\mathrm{G} 1$ phase of cell cycle. shown). Scale bar $50 \mu \mathrm{m}$. One-way ANOVA test showed $p<0.0005$ for $\left[{ }^{3} \mathrm{H}\right]$-thymidine incorporation and $p<0.005$ for immunoblot analysis. Unpaired Student's $t$ test analyses $(* p<0.05, * * p<0.005$, *** $p<0.0005)$. Results are represented as mean $\pm \mathrm{SD}(n=3$ in quadruplicates for $\left[{ }^{3} \mathrm{H}\right]$-thymidine incorporation and mitochondria viability, and triplicates for immunoblot analysis)

In Vivo Effect of Ep-CM in the Muscular Lesion

Skeletal muscle remodeling during degeneration and regeneration is accompanied by high turnover of extracellular matrix components (Carmeli et al. 2004; Kherif et al. 1999). Increased MMP-9 activation during the acute stage of Bp-induced inflammation (1 day post-injection) in C57 mice is important for collagen degradation and facilitation of leukocyte migration with phagocytic properties for clearance of cell debris (Lagrota-Candido et al. 2010). After 4 days of in vivo induction of muscular lesion and $E p$-CM elvax implant for slow release of pentacyclic triterpenes, a reduction of MMP-9 activity was observed ( $35 \pm 7 \%, p<0.05)$; but there was no difference concerning MMP-2 activity in the muscular lesion, compared to $\mathrm{C} 57 \mathrm{BL} / 10$ control and DMSO vehicle-treated muscles (Fig. $7 \mathrm{a}-\mathrm{c}$ ). In addition, $E p-C M$ implant reduced the inflammatory lesion area in the gastrocnemius muscle and augmented muscular regeneration evidenced by basophilic centronucleate fibers (Fig. 7d) with HE staining and also promoted tissue remodeling without inducing fibrosis as shown by mild collagen deposition with sirius red staining. Conversely, vehicle-treated mice showed pronounced inflammatory lesion area and scarce muscle fibers at early stage of regeneration (Fig. 7d). 

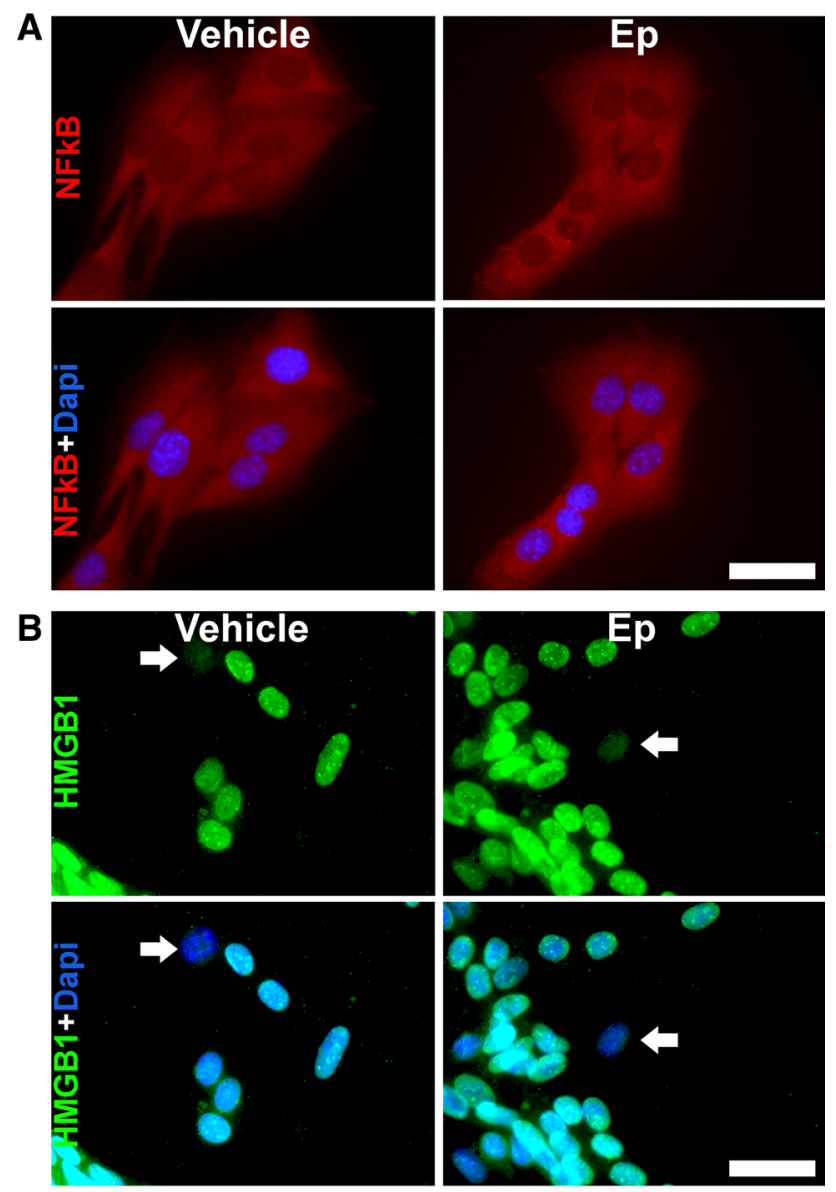

C
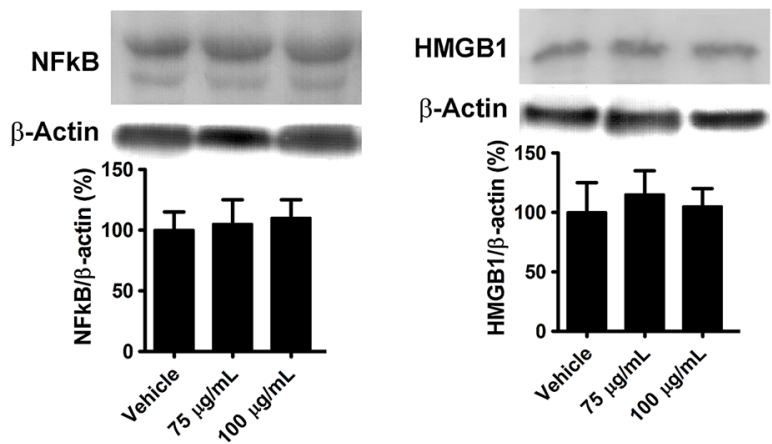

Fig. 5 Effect of Ep-CM upon NFאB activation and HMGB1 production. Immunocytochemistry of a NFKB and b HMGB1 with merged images with Dapi after treatment with vehicle or $E p-C M$ $100 \mu \mathrm{g} / \mathrm{mL}$. White arrows indicate low HMGB1 immunolabeling on cellular nuclei of both groups. Negative control did not show immunoreactivity (data not shown). Scale bar $50 \mu \mathrm{m}$. c Immunoblots analysis of NFKB and HMGB1 content after Ep-CM treatment with 75 and $100 \mu \mathrm{g} / \mathrm{mL}$. 43-kDa $\beta$-actin was used as loading control ( $n=3$ in triplicates for all assays)

\section{Discussion}

The present work shows that $E p-C M$ containing pentacyclic triterpenes as major component inhibits $\mathrm{C} 2 \mathrm{C} 12$ myoblast cell proliferation in a dose-dependent manner with no effect on cell death induction by apoptosis or necrosis. Additionally, in response to in vivo muscular injury, $E p-C M$ increased tissue remodeling evidenced by marked reduction of inflammatory reaction and collagen deposition, and an increase in the area of regeneration. Inflammation and cell death by necrosis often occurs whenever HMGB1 is translocated to the cytoplasm and secreted into the extracellular medium (Lange and Vasquez 2009). Therefore, HMGB 1 translocation from nucleus to cytoplasm was chosen as important an indication of maintenance of structural dynamics and DNA repair. Alteration in the levels and HMGB1 cytoplasmic translocation after $E p-C M$ treatment was not observed. These data combined with live-dead results indicate that $E p-C M$ treatment did not induce cell death by necrosis. Ep-CM effect was considered reversible, because the inhibitory effect upon cell proliferation only occurred while $E p-C M$ was available in the culture medium, and reconstitution by fresh medium completely abolished such effects. Different signaling pathways control cell proliferation and differentiation, MAPK and NFKB being two of the most important. The inhibitory effect of $E p-C M$ on $\mathrm{C} 2 \mathrm{C} 12$ proliferation was comparable to the classic specific inhibitor of MEK1 phosphorylation PD98059 (Tortorella et al. 2001). Likewise, reduced $\mathrm{pERK}$ immunostaining with no alteration on activation and nuclear translocation of $\mathrm{NF \kappa B}$ suggest that Ep-CM cytostatic effect may be via inhibition of MAPK signaling pathway with consequent reduction of ERK phosphorylation.

Cell proliferation is a complex phenomenon involving coordinate interaction of cyclins (A, B, D and E), cyclindependent kinases and cyclin-dependent kinase inhibitors (Stamatakos et al. 2010; Traganos 2004; Yang et al. 2006). The MTT assay measures cellular metabolic activity of NADPH-dependent cellular oxireductase enzymes and also cytotoxicity (loss of viable cells) or cytostatic activity (shift from proliferative to resting status) of potential medicinal agents and toxic materials. Resting cells that are viable but metabolically quiescent reduce very little MTT, but rapidly dividing cells such as $\mathrm{C} 2 \mathrm{C} 12$ exhibit high rates of MTT reduction. Ep-CM reduced expression of cyclin D1 that is important for cell cycle progression during the G1 phase (Favreau et al. 2008; Jones and Kazlauskas 2001), but increased p2 $7^{\mathrm{Kip} 1}$ levels an inhibitor of cyclin/CDK interaction that prevents cell cycle progression of during the G1 phase (Deng et al. 2004). The in vitro effect of $E p$-CM increasing pAkt content suggests a role in the activation of early $\mathrm{C} 2 \mathrm{C} 12$ myoblast cell differentiation program. Such results indicate that triterpenes in the $E p-C M$ fraction reduced proliferation of $\mathrm{C} 2 \mathrm{C} 12$ cells mainly due to its cytostatic effect without influencing the metabolic activity. In order to confirm such hypothesis, it is important to further analyze expression of p53 and oxidative stress. Nonetheless, quantification of cell proliferation with 

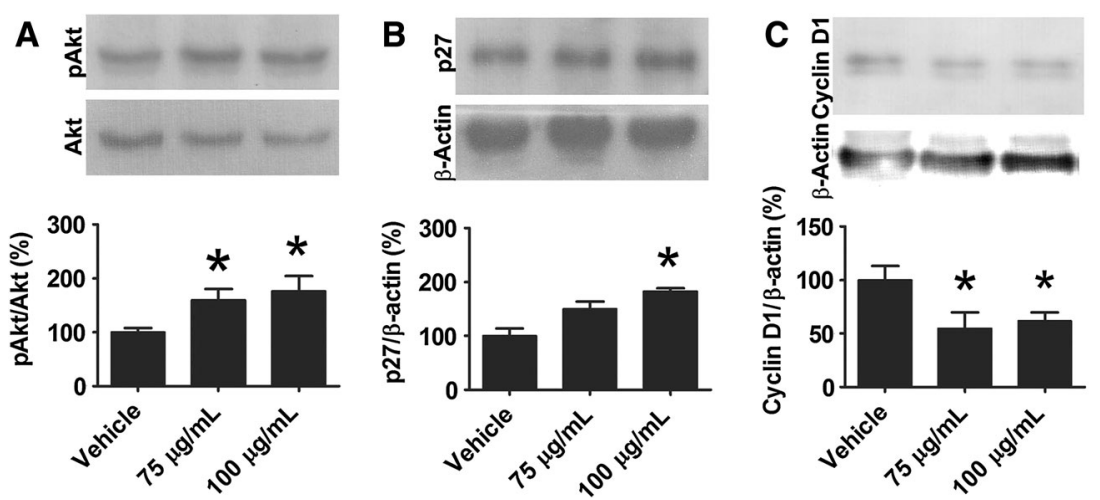

Fig. 6 Ep-CM influences $\mathrm{C} 2 \mathrm{C} 12$ cell cycle. Immunoblot analysis of a pAkt, b p27 and c Cyclin D1 content after Ep-CM. Total Akt or $43-\mathrm{kDa} \beta$-actin were used as loading controls. One-way ANOVA test showed $p<0.05$ for pAkt and $\mathrm{p} 27$, and $p<0.01$ for Cyclin D1

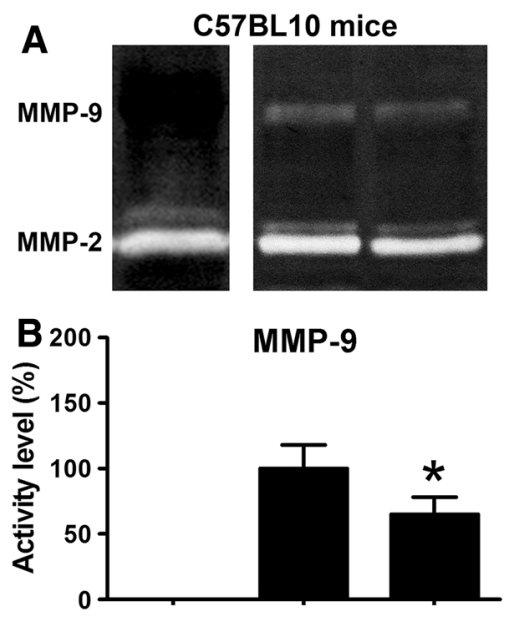

Fig. $7 E p$ - $C M$ treatment reduces in vivo activity of MMP-9 but not MMP-2. a Gelatin zymogram of gastrocnemius skeletal muscle from C57BL/10 mice showing the activity levels of $\mathbf{b}$ MMP-9 and $\mathbf{c}$ MMP2. Control group: without muscular lesion and Ep-CM treatment; Bpinduced muscular lesion without $E p$-CM treatment (-) and mice 4 days after $E p-C M$ treatment (+). d Histological photomicrographs of C57BL/10 mice Bp-induced muscular lesion treated with vehicle DMSO or Ep-CM stained with hematoxylin-eosin and sirius red for collagen deposition. One-way ANOVA test for MMP-9 showed $p<0.0005$. Unpaired Student's $t$ test analysis $(* p<0.05)$. Results are represented as mean $\pm \mathrm{SD}(n=3)$

tritiated-thymidine incorporation confirmed the Ep-CM cytostatic effect.

Muscular tissue presents an organized structure formed by a mesh of extracellular matrix molecules and endothelial vascular cells closely associated with fibroblasts, myoblasts, satellite cells and inflammatory leukocytes that are important sources of MMP-9 and MMP-2 (Kherif et al. 1999; Roach et al. 2002). During repair of injured or inflamed muscle, tissue remodeling is accompanied by high turnover of extracellular matrix components that contribute immunoblot analysis. Unpaired Student's $t$ test analyses $(* p<0.05)$. Results are represented as mean $\pm \mathrm{SD}(n=3$ in triplicates for all immunoblots)

to formation, differentiation and elongation of myotubes into myofibres. MMPs are main proteolytic system responsible for the extracellular matrix turnover in skeletal muscles. Expression and activity of MMPs are regulated by mechanical stimulation, and influence extracellular matrix remodeling surrounding adjacent muscle fibers for expansion and proliferation of individual muscle fiber (Cha and Purslow 2010). Interestingly, in vitro experiments showed that $E p-C M$ treatment increased secretion of both MMPs. Such results are probably because mechanical deformation and secretion of the extracellular matrix component collagen-type 1 by myoblasts act as potent inducers of gelatinolytic activity by $\mathrm{C} 2 \mathrm{C} 12$ myoblasts growing on noncoated plates (Cha and Purslow 2010). The in vivo effect of $E p-C M$ treatment reducing MMP-9 activity and leukocyte infiltration but increasing the area of muscular regeneration with numerous regenerating fibers with centrally located nuclei and mild collagen deposition in the bupivacaineinduced muscular lesion, confirmed (Leite et al. 2010) the anti-inflammatory potential of the $E p-C M$ compound in the field of regenerative medicine.

Acknowledgments This study was supported by grants from Coordenação de Aperfeiçoamento de Pessoal de Nível Superior (CAPES), Conselho Nacional de Pesquisa e Desenvolvimento Tecnológico (CNPq), and Fundação de Amparo a Pesquisa do Rio de Janeiro (FAPERJ). WCS is a member of Redoxoma INCT of Redox Process in Biomedicine funded by CNPq/FAPESP.

Conflict of interest All authors that participated in this study declare that they have nothing to disclose regarding competing interests or funding from industry with respect to this manuscript. Paulo Emilio Leite participated in this work including study design, data collection, analysis, interpretation, statistical analysis, and manuscript preparation. Katia Lima-Araújo and Wilson C. Santos participated in this study including plant extract processing, and structural characterization of organic isolates. Guilherme França participated in this study including collection, analysis and interpretation of cell signaling data. Jussara Lagrota-Candido participated in 
the manuscript revision. Thereza Quirico-Santos participated in the study design, analysis and interpretation of data, manuscript preparation and revision.

\section{References}

Azouz A, Razzaque MS, El-Hallak M et al (2004) Immuno inflammatory responses and fibrogenesis. Med Electron Microsc 37:141-148

Bopp A, De Bona KS, Belle LP et al (2009) Syzygium cumini inhibits adenosine deaminase activity and reduces glucose levels in hyperglycemic patients. Fundam Clin Pharmacol 23:501-507

Brito FA, Lima LA, Ramos MF et al (2007) Pharmacological study of anti-allergic activity of Syzygium cumini (L.) Skeels. Braz J Med Biol Res 40:105-115

Carmeli E, Moas M, Reznick AZ et al (2004) Matrix metalloproteinases and skeletal muscle: a brief review. Muscle Nerve 29:191-197

Cha MC, Purslow PP (2010) The activities of MMP-9 and total gelatinase respond differently to substrate coating and cyclic mechanical stretching in fibroblasts and myoblasts. Cell Biol Int 34:587-591

Consolini AE, Sarubbio MG (2002) Pharmacological effects of Eugenia uniflora (Myrtaceae) aqueous crude extract on rat's heart. J Ethnopharmacol 81:57-63

de Pascual R, Colmena I, de Los Rios C et al (2012) Augmentation of catecholamine release elicited by Eugenia punicifolia extract in chromaffin cells. Rev Bras Farmacogn 22:1-12

Deng X, Mercer SE, Shah S et al (2004) The cyclin-dependent kinase inhibitor p $27^{\mathrm{Kip} 1}$ is stabilized in $\mathrm{G}(0)$ by Mirk/dyrk1B kinase. J Biol Chem 279:22498-22504

dos Santos KK, Matias EF, Tintino SR et al (2012) Cytotoxic, trypanocidal, and antifungal activities of Eugenia jambolana L. J Med Food 15:66-70

Favreau C, Delbarre E, Courvalin JC et al (2008) Differentiation of C2C12 myoblasts expressing lamin A mutated at a site responsible for Emery-Dreifuss muscular dystrophy is improved by inhibition of the MEK-ERK pathway and stimulation of the PI3-kinase pathway. Exp Cell Res 314:1392-1405

Grangeiro MS, Calheiros-Lima AP, Martins MF et al (2006) Pharmacological effects of Eugenia punicifolia (Myrtaceae) in cholinergic nicotinic neurotransmission. J Ethnopharmacol 108:26-30

Jones SM, Kazlauskas A (2001) Growth factor-dependent signaling and cell cycle progression. FEBS Lett 490:110-116
Kherif S, Lafuma C, Dehaupas M et al (1999) Expression of matrix metalloproteinases 2 and 9 in regenerating skeletal muscle: a study in experimentally injured and mdx muscles. Dev Biol 205:158-170

Lagrota-Candido J, Canella I, Pinheiro DF et al (2010) Characteristic pattern of skeletal muscle remodelling in different mouse strains. Int J Exp Pathol 91:522-529

Lange SS, Vasquez KM (2009) HMGB1: the jack-of-all-trades protein is a master DNA repair mechanic. Mol Carcinog 48:571-580

Lee CH, Jeon YT, Kim SH et al (2007) NF-kappaB as a potential molecular target for cancer therapy. Biofactors 29:19-35

Leite PE, Lagrota-Candido J, Moraes L et al (2010) Nicotinic acetylcholine receptor activation reduces skeletal muscle inflammation of mdx mice. J Neuroimmunol 227:44-51

Mosmann T (1983) Rapid colorimetric assay for cellular growth and survival: application to proliferation and cytotoxicity assays. J Immunol Methods 65:55-63

Mussini I, Favaro G, Carraro U (1987) Maturation, dystrophic changes and the continuous production of fibers in skeletal muscle regenerating in absence of nerve. J Neuropathol Exp Neurol 46:315-331

Rahimi R, Ghiasi S, Azimi H et al (2010) A review of the herbal phosphodiesterase inhibitors; future perspective of new drugs. Cytokine 49:123-129

Roach DM, Fitridge RA, Laws PE et al (2002) Up-regulation of MMP-2 and MMP-9 leads to degradation of type IV collagen during skeletal muscle reperfusion injury; protection by the MMP inhibitor, doxycycline. Eur J Vasc Endovasc Surg 23:260-269

Stamatakos M, Palla V, Karaiskos I et al (2010) Cell cyclins: triggering elements of cancer or not? World J Surg Oncol 8:111

Talhouk RS, Bissell MJ, Werb Z (1992) Coordinated expression of extracellular matrix-degrading proteinases and their inhibitors regulates mammary epithelial function during involution. J Cell Biol 118:1271-1282

Tortorella LL, Milasincic DJ, Pilch PF (2001) Critical proliferationindependent window for basic fibroblast growth factor repression of myogenesis via the p42/p44 MAPK signaling pathway. J Biol Chem 276:13709-13717

Traganos F (2004) Cycling without cyclins. Cell Cycle 3:32-34

Wang H, Liao H, Ochani M et al (2004) Cholinergic agonists inhibit HMGB1 release and improve survival in experimental sepsis. Nat Med 10:1216-1221

Yang K, Guo Y, Stacey WC (2006) Glycogen synthase kinase 3 has a limited role in cell cycle regulation of cyclin D1 levels. BMC Cell Biol 7:33 